\title{
Sociedade e Natureza no Pontal do Paranapanema - SP: a unidade da geografia e o desenvolvimento regional
}

\author{
Society and nature in the Pontal do Paranapanema - SP: the unit of geography \\ and regional development
}
Sociedad y naturaleza en el Pontal de Paranapanema - SP: perspectiva geográfica para el desarrollo regional

\author{
Ricardo dos Santos 1 \\ Estevan Leopoldo de Freitas $\mathrm{Coca}^{2}$
}

Recebido em 04/2017 - aceito em 07/2017.

\begin{abstract}
RESUMO: Nesse texto a Geografia é entendida na perspectiva de sua totalidade, de modo que sociedade e natureza se relacionam por meio de um processo dialético. Tendo essa referência, é feita a defesa de que ações que visam contribuir com o desenvolvimento regional devem levar em consideração todas as dimensões da realidade e não apenas a econômica, como tem sido comum no modelo capitalista. Como recorte é utilizada a região do Pontal do Paranapanema, no Estado de São Paulo. Destaca-se como no Pontal do Paranapanema coexistem diferentes modelos de desenvolvimento, todavia, a prevalência tem sido o de cunho capitalista.
\end{abstract}

Palavras-chave: Sociedade; Natureza; Pontal do Paranapanema.

ABSTRACT: In this paper Geography is understood in the perspective of its totality, so that society and nature are related through a dialectical process. Therefore, it is made a defense that actions aimed at contributing to regional development have to consider all dimensions of reality and not only the economic on as in the capitalist model. As a scale it is used in the region of Pontal do Paranapanema, in the State of São Paulo. It stands out as in the Pontal do Paranapanema coexist different models of development, nevertheless, a prevalence has been the capitalist one.

Keywords: Society; Nature; Pontal do Paranapanema.

RESUMEN: En el texto, la Geografía es entendida como totalidad, donde la naturaleza y la sociedad se relacionan dialécticamente. Con ese fundamento se defiende que, las acciones para contribuir al desarrollo regional, deben considerar todas las dimensiones de la realidad y no solo la económica, como ha sido común en el modelo capitalista. Como recorte espacial se utiliza la región del Pontal de Paranapanema en el Estado de Sao Paulo, donde coexisten diferentes modelos de desarrollo, aunque prevalece el modelo capitalista.

Palabras claves: sociedad; naturaleza; Pontal de Paranapanema

\section{INTRODUÇÃO}

Uma das heranças do positivismo na Geografia é a compreensão fragmentária da ciência. Isso pode ser percebido pela prevalência do modelo Natureza-HomemEconomia ( $\mathrm{N}-\mathrm{H}-\mathrm{E})$, onde a primeira é vista como uma máquina, o segundo como estatístico e o terceiro como fragmentado (MOREIRA, 2006). Substituir o modelo N-H- 
E por outro que valorize uma compreensão totalizante da realidade se faz um desafio para a Geografia que se forma no atual período da ultramodernidade. Em razão disso, no presente texto, trazemos uma leitura sobre a importância de se considerar de maneira holística a sociedade e a natureza na discussão sobre o desenvolvimento regional.

Como recorte é utilizada a região do Pontal do Paranapanema, localizada à oeste do Estado de São Paulo, integrando sua 10ª Região Administrativa. Constituído por 32 municípios que integram o oeste do Estado de São Paulo, o Pontal do Paranapanema está localizado entre a confluência dos rios Paraná e Paranapanema, na divisa entre os Estados de Mato Grosso do Sul e Paraná (Figura 1). Região conhecida nacionalmente e mundialmente por diversos conflitos pela terra (FERNANDES, 1994), teve uma ocupação relativamente tardia no contexto da história do Brasil por volta do início do século XIX (MONBEIG, 1984), caracterizando-se majoritariamente pela apropriação irregular de extensas terras públicas conhecidas como devolutas, sendo o caso de grilagem de terras mais conhecido no país (LEITE, 1998). Além disso, a região teve sua paisagem significativamente modificada pela ação antrópica com intensa degradação ambiental, supressão da vegetação natural e genocídio de populações indígenas, para subsidiar os interesses do capital nacional e internacional (SOBREIRO FILHO, 2013).

Extensas áreas de Mata Atlântica de interior que compunha a "Grande Reserva do Pontal" foram gradativamente desmatadas (LEITE, 1998), cedendo espaço para cultivo de café e posteriormente, a pecuária extensiva que predomina o cenário na atualidade (COCA, 2016), paralelamente à expansão da cultura de cana de açúcar no contexto da expansão de grandes empresas agroindustriais (THOMAZ JÚNIOR, 2013). Devido às suas características peculiares, influenciadas em grande parte pelo seu processo de ocupação histórica, problemas de gestão aliados a interesses políticos, o Pontal do Paranapanema na atualidade apresenta diversos desafios ambientais, econômicos e sociais, sendo considerada uma das regiões mais pobres do Estado (MAZZINI, 2007).

Assim, buscando contribuir com a possibilidade de uma leitura da totalidade do Pontal do Paranapanema pelo viés da Geografia, a metodologia desse trabalho está pautada em pesquisas realizadas e a partir de alguns resultados obtidos na região por Santos (2010) e Coca (2016). Também serão analisados alguns dados secundários da região oriundos de órgãos públicos. 
Figura 1 - Localização do Pontal do Paranapanema na 10ª Região Administrativa do Estado de São Paulo

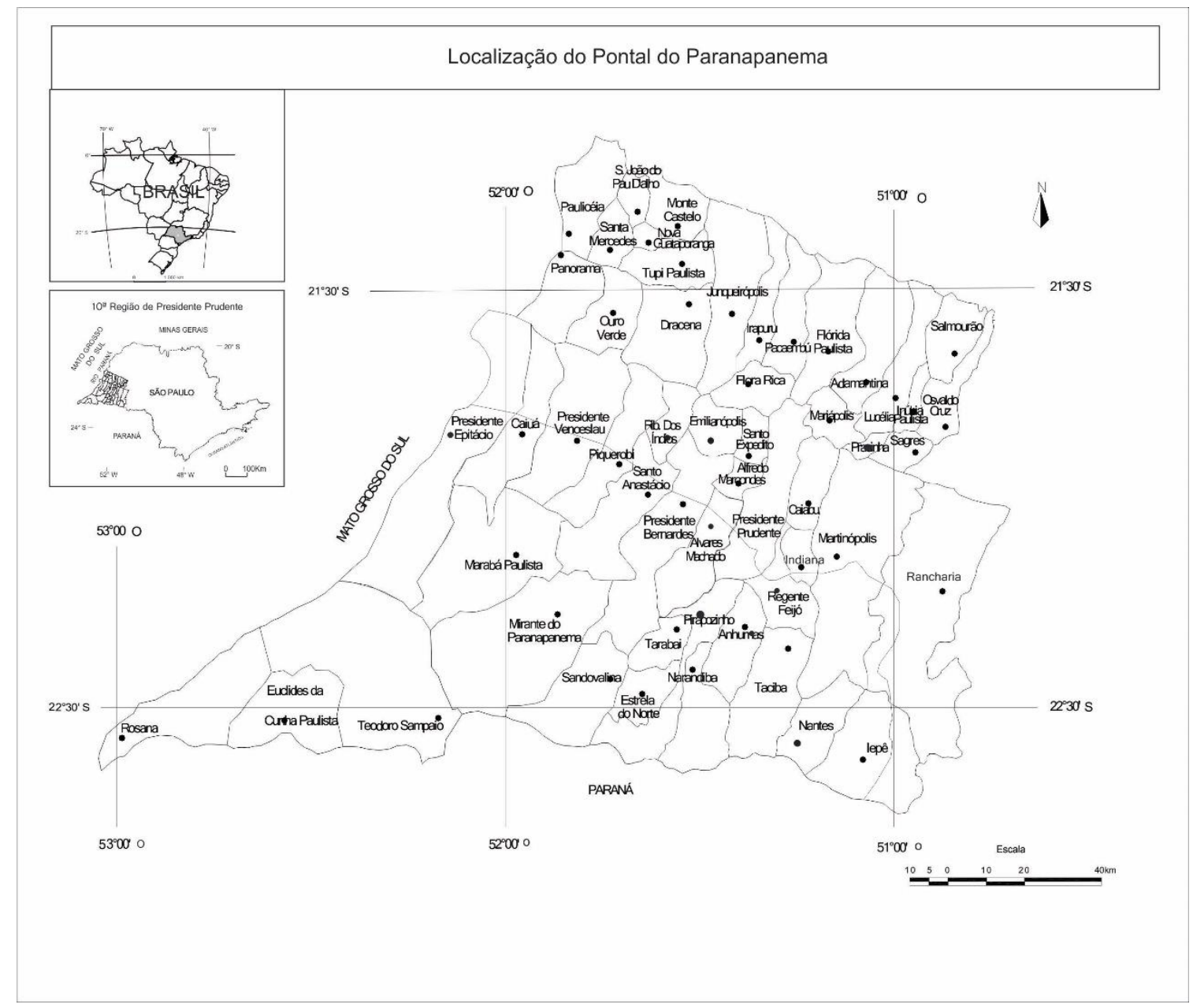

Fonte: Comitê da Bacia Hidrográfica do Pontal do Paranapanema, 2008. Organizado pelos autores.

\section{DESENVOLVIMENTO}

Os grandes dilemas da sociedade atual podem ser compreendidos pela ausência de estudos e ações integradas que abarquem todos os aspectos da realidade, sejam eles ambientais, sociais, econômicos ou políticos. Normalmente, os aspectos econômicos e políticos são privilegiados em detrimento dos aspectos sociais e ambientais, no contexto do sistema capitalista.

Refletindo sobre a produção científica a partir do modelo positivista e neopositivista, estes compreendiam a realidade fragmentada como se o todo fosse a mera junção das partes, com um conhecimento desvinculado da realidade social, onde as partes não se relacionavam para a compreensão dos fenômenos. Esse pensamento predominante nas ciências de modo geral e também na Geografia, contribuiu para que aspectos da dinâmica da natureza e da sociedade fossem desvinculados e a natureza compreendida como algo externo à sociedade. $\mathrm{Na}$ 
compreensão de Moreira (2006), isso redundou na leitura de um homem atópico, que é aquele que está na natureza, mas não faz parte dela.

Pode-se dizer que a Geografia adentrou numa ruptura paradigmática, levandoa a ser criticada por um conhecimento superficial, aliado a uma confusão referente a definição do seu objeto de estudo e questionamento sobre suas bases científicas (Pensamento reducionista-mecanicista herdado dos filósofos da Revolução Científica do século XVII, como Descartes, Francis Bacon e Newton). A grande limitação da influência de tais bases filosófica na análise geográfica é que elas situavam o espaço como um a priori, ou então um receptáculo, ou seja, ele era fetichizado (LENCIONI, 1999).

Leff (2006, p.60) aponta como marco que culminou com a crise ambiental atual o processo histórico em que emergiu a ciência moderna e a Revolução Industrial. De acordo com o autor:

[...] Este processo deu lugar ao fracionamento do conhecimento e à compartimentalização da realidade em campos disciplinares confinados, com o propósito de incrementar a eficácia do saber científico e a eficiência da cadeia tecnológica de produção. A partir dessa premissa, iniciou-se a busca por um método capaz de reintegrar esses conhecimentos dispersos num campo unificado do saber. Desta forma, a análise da questão ambiental exigiu uma visão sistêmica e um pensamento holístico para a reconstituição de uma realidade "total". Daí propôs um projeto para pensar as condições teóricas e para estabelecer métodos que orientem as práticas da interdisciplinariedade (LEFF, 2006, p. 60).

Alguns aspectos referentes à crise ambiental na atualidade são mencionados por Rodriguez e Silva (2009), quando esclarecem que a Questão Ambiental no mundo se deve aos paradigmas científico-filosóficos dominantes da atualidade, construídos tendo como base as correntes filosóficas e o desenvolvimento das ciências a partir da época moderna (século XVII). Segundo os autores, esses paradigmas que denominam de mecanicista-racionalistas influenciaram o mundo ocidental, permitindo modelos de desenvolvimento que se tornaram incompatíveis com a estabilidade do meio, culminando com a crise ambiental atual.

Entre outros problemas do paradigma mecanicista-racionalista, Rodriguez e Silva (2009) destacam que a abordagem da questão ambiental restringe a natureza através de uma visão reducionista (visualização da natureza como uma totalidade fragmentária), sendo o ser humano analisado isoladamente de sua condição social. Esse pensamento influenciou nas teorias e práticas do desenvolvimento a partir da década de 50 do século $\mathrm{XX}$, concebendo o desenvolvimento como crescimento econômico, desconsiderando a questão ambiental do processo de desenvolvimento. 
É neste contexto que a ocupação do Pontal do Paranapanema necessita ser analisada, considerando suas disparidades e desafios ainda muito presentes na atualidade. Isso porque, as disputas por diferentes modelos de desenvolvimento nessa região tem repercutido na construção de arranjos espaciais que ora se inserem na dinâmica capitalista e ora vão no sentido contrário a ela, todavia, predominando a primeira tendência.

Segundo Leite (1998), até o início do século XIX, a região era praticamente desconhecida pelas elites do país, sendo habitada por tribos indígenas como Xavantes, Caingangs e Caiuás. Apenas os bandeirantes desbravadores conheciam a região, buscando aprisionar índios para o trabalho escravo e a princípio, não tinham a intenção de permanecer na área.

De acordo com Leite (1998), a história de grilagem de terras do Pontal do Paranapanema teve seu início em 1856, a partir da chegada de Antônio José Gouvêa, um dos pioneiros que assentou junto aos registros paroquiais, uma imensa gleba de terras, denominada de Fazenda Pirapó-Santo Anastácio. Registros atestam que desde o início do século XX é conhecida a falsidade dos documentos referentes a essa gleba. Entretanto, a partir de 1920, a região teve sua ocupação intensificada, a partir do crescimento da economia cafeeira e da necessidade de anexação de novas terras à um mercado fundiário que se expandia (MONBEIG, 1984). A partir de 1940, o governo estadual, tentando retomar o controle dessas terras, implanta na região uma imensa reserva florestal denominada Grande Reserva do Pontal. Porém, as grilagens continuavam acontecendo, culminando com a ocupação de toda a região, restando apenas o Parque Estadual do Morro do Diabo, em Teodoro Sampaio, existente até hoje.

As primeiras contestações a esses grilos de terras ocorreram no princípio da segunda metade do século XX, sendo exemplos os que ocorreram na Fazenda Lagoa São Paulo, em Presidente Epitácio e na Fazenda Rebojo, em Estrela do Norte (FELICIANO, 2009; FERNANDES, 1994; LEITE, 1998). Essas, tiveram caráter apenas pontual. Contudo, na década de 1990 surge um novo personagem na luta pela terra no Pontal do Paranapanema: "[...] o trabalhador expropriado, expulso, excluído, marginalizado, que faz parte da reserva de mão-de-obra à disposição dos capitalistas, que no movimento da luta foi se denominando trabalhador sem-terra" (FERNANDES, 1994, p.96-97).

Nessa conjuntura, surgiram os primeiros movimentos socioterritoriais no Pontal do Paranapanema, agrupando milhares de agricultores familiares/camponeses que reivindicavam o acesso à terra. Eles passaram a utilizar a ocupação como principal 
tática de luta pela terra, criando uma grande conflitualidade com os latifundiários (FERNANDES, 1994).

Os primeiros anos da década de 1990 foram marcados pela estruturação do Movimento dos Trabalhadores Rurais Sem-Terra (MST) no Pontal do Paranapanema, colocando a luta pela terra como um importante elemento da Questão Agrária nessa região.

Foram constituídas condições básicas de organização, criadas estratégias para a luta, estruturados acampamentos e criados setores e núcleos para lidar com as necessidades do movimento, como: saúde; educação; disciplina; comunicação; finanças; frente de massa; etc. (SOBREIRO FILHO, 2013, p. 219).

Vale frisar que de 1996 em diante, outros movimentos de luta pela terra, além do MST, passaram a atuar no Pontal do Paranapanema. Dentre os motivos, podem ser elencadas as dissensões ocasionadas por diferenças políticas e ideológicas no interior desses movimentos socioterritoriais do campo. O primeiro desses a realizar uma ocupação de terra foi o Movimento Brasileiros Unidos Querendo Terra (MBUQT), que foi formado por um grupo de arrendatários do município de Presidente Venceslau, os quais não concordavam com o modo de ação do MST (MACIEL, 2009). Além dele, merece destaque o surgimento do Movimento dos Agricultores Sem-terra (MAST) no final da década de 1990, que também trouxe como proposta criar uma alternativa ao protagonismo do MST na luta pela terra. O MAST surgiu com um forte vínculo com o Partido da Social Democracia Brasileira (PSDB), apoiando as políticas neoliberais efetivadas pelos governos Federal e Estadual nesse período (FELICIANO, 2006). Como uma dissidência do MAST, no ano de 2006 surgiu no Pontal do Paranapanema o Movimento dos Trabalhadores Sem Terra (MTST).

Contudo, a principal fratura vivida na expressão da luta pela terra no Pontal do Paranapanema se deu com a saída de José Rainha Júnior do MST e a formação de um novo movimento socioterritorial camponês, o MST da Base ${ }^{3}$. Rainha Júnior foi a principal liderança do MST no Pontal do Paranapanema na década de 1990. Contudo, no princípio da década de 2000, alegando divergências na forma de organizar a luta pela terra, o MST o afastou dos seus quadros de representação nacional, estadual e regional, ou seja, ele deixou de ser autorizado a falar pelo movimento. Ocorre que mesmo assim, Rainha Júnior continuou trabalhando na organização de agricultores familiares/camponeses para a luta pela terra, usando para isso o nome e símbolos do MST. (SOBREIRO FILHO, 2013).

Como resultado dessa ampla conflitualidade, entre 1988 e 2014 foram realizadas 838 ocupações, com a participação de 138.295 famílias no Pontal do 
Paranapanema (Tabela 01). Apenas 6 dos seus 32 municípios não tiveram esse conflito fundiário. Por esses números, o Pontal do Paranapanema se destaca como a região com maior número de ocupações pela terra no estado de São Paulo, com 53\% do total e $66 \%$ das famílias.

\begin{tabular}{|c|c|c|}
\hline Município & Ocupações & Famílias \\
\hline Álvares Machado & 5 & 154 \\
\hline Caiuá & 45 & 2.848 \\
\hline Emilianópolis & 2 & 60 \\
\hline $\begin{array}{lll}\text { Euclides da } & \text { Cunha } \\
\text { Paulista } & & \\
\end{array}$ & 57 & 7.011 \\
\hline lepê & 13 & 574 \\
\hline João Ramalho & 5 & 209 \\
\hline Marabá Paulista & 34 & 4.594 \\
\hline Martinópolis & 51 & 2.600 \\
\hline $\begin{array}{ll}\text { Mirante } & \text { do } \\
\text { Paranapanema } & \\
\end{array}$ & 174 & 33.540 \\
\hline Nantes & 4 & 465 \\
\hline Narandiba & 5 & 417 \\
\hline Piquerobi & 9 & 302 \\
\hline Pirapozinho & 7 & 900 \\
\hline Presidente Bernardes & 58 & 3.6755 \\
\hline Presidente Epitácio & 83 & 9.211 \\
\hline Presidente Prudente & 4 & 620 \\
\hline Presidente Venceslau & 54 & 2.652 \\
\hline Rancharia & 47 & 6.336 \\
\hline Regente Feijó & 5 & 75 \\
\hline Ribeirão dos Índios & 1 & 60 \\
\hline Rosana & 23 & 2.197 \\
\hline Sandovalina & 45 & 12.794 \\
\hline Santo Anastácio & 15 & 1.464 \\
\hline Taciba & 2 & 190 \\
\hline Tarabai & 6 & 638 \\
\hline Teodoro Sampaio & 84 & 11.629 \\
\hline TOTAL & 838 & 138.295 \\
\hline
\end{tabular}

Vale ressaltar que a ocupação de terra é uma ação com forte cunho político, mas que também remete a uma proposta de manejo da terra diferente da que é implementada no modelo capitalista de agricultura. Por ser efetivada por agricultores familiares/camponeses, ela visa criar condições para o estabelecimento de práticas 
agrícolas baseadas na pequena produção policultora, com vistas ao mercado interno, sendo muito pouco recorrente o uso de insumos químicos.

Como resultado desses conflitos por terra, no Pontal do Paranapanema, entre 1985 e 2014 foram implantados 114 assentamentos rurais, com 6.014 famílias, ocupando 142.427 ha (Tabela 02). Essas intervenções fundiárias causaram consideráveis impactos socioterritoriais em diversos municípios da região (MAZZINI, 2007) contribuindo para a construção de alternativas ao modelo de desenvolvimento capitaneado pelo agronegócio. Mesmo com diversas limitações produtivas, esses assentamentos rurais trazem uma perspectiva de relação sociedade-natureza pautada em valores como a Agroecologia e a soberania alimentar, indo além do modelo capitalista.

Contudo, mesmo sendo o Pontal do Paranapanema uma das regiões com maior presença de projetos de reforma agrária no Brasil (REDE DATALUTA, 2014), nele ainda existe uma considerável concentração fundiária. As unidades de produção familiar/camponesas são $76,11 \%$ do total, porém, ocupam apenas $22,14 \%$ da área. Isso indica que apesar de ter gerado diversos impactos socioterritoriais, a política de reforma agrária não tem sido pensada como elemento estruturante do desenvolvimento regional, pois prevalece o modelo do agronegócio.

A principal atividade econômica no campo é a pecuária e a criação de outros animais. Ela está presente em $81,46 \%$ das unidades de produção e em $80,54 \%$ da área ocupada (IBGE, 2006). A criação de bovinos é realizada tendo duas principais finalidades: o corte e a produção de leite. A maior explicação para o predomínio da pecuária extensiva em toda a região do Pontal do Paranapanema na atualidade devese principalmente às características do solo. Este é predominantemente do tipo latossolo, constituídos a partir do Grupo Bauru, que possui elevada concentração de areia, fertilidade natural baixa, boa permeabilidade e drenagem excessiva (ITESP, 1999). Essas características, aliadas ao esgotamento rápido do seu potencial, acabaram dificultando as práticas agrícolas que exigiam cada vez mais intervenções caras para sua adequação aos plantios, além da alta susceptibilidade à erosão devido às características naturais do solo e agravadas com a retirada parcial ou total da vegetação, inclusive retirada da mata ciliar dos cursos d'água. Assim, não houve respeito às Áreas de Preservação Permanentes (APPs) conforme prevê a legislação vigente, embora muitos problemas ambientais tenham sido iniciados em áreas anteriores as demarcações das APPs (topo ou vertente do relevo). (SANTOS, 2010). 
Tabela 02 - Pontal do Paranapanema - Assentamentos Rurais - 1985-2012

\begin{tabular}{l|l|l|l}
\hline Município & $\begin{array}{l}\text { No } \\
\text { Assentamentos }\end{array}$ & $\begin{array}{l}\text { No } \\
\text { Famílias }\end{array}$ & $\begin{array}{l}\text { Área em } \\
\text { ha }\end{array}$ \\
\hline Caiuá & 8 & 441 & 10.736 \\
\hline Euclides da Cunha Paulista & 9 & 511 & 10.935 \\
\hline lepê & 1 & 36 & 68 \\
\hline João Ramalho & 1 & 29 & 55 \\
\hline Marabá Paulista & 6 & 257 & 6.481 \\
\hline Martinópolis & 2 & 122 & 2.745 \\
\hline Mirante do Paranapanema & 35 & 1.546 & 35.470 \\
\hline Piquerobi & 3 & 84 & 2.595 \\
\hline Presidente Bernardes & 8 & 264 & 7.193 \\
\hline Presidente Epitácio & 4 & 340 & 6.088 \\
\hline Presidente Venceslau & 8 & 378 & 10.101 \\
\hline Rancharia & 2 & 175 & 4.265 \\
\hline Rosana & 4 & 766 & 18.307 \\
\hline Sandovalina & 2 & 198 & 4.017 \\
\hline Teodoro Sampaio & 21 & 867 & 23.371 \\
\hline TOTAL & $\mathbf{1 1 4}$ & $\mathbf{6 . 0 1 4}$ & $\mathbf{1 4 2 . 4 2 7}$ \\
\hline
\end{tabular}

Fonte: DATALUTA, 2015. Org.: Os autores.

Em toda a região, identificam-se diversos problemas sociais e ambientais. Alguns problemas do Pontal do Paranapanema, foram mencionados por Leal (2000) como a perda acentuada de água superficial provocada pelo intenso desmatamento e aceleração do processo erosivo em áreas urbanas e rurais; assoreamento e desperenização de cursos d'água; deposição irregular de resíduos em nascentes e fundos de vales; exploração sem controle da água subterrânea; solos agricultáveis e fertilizantes carregados para os cursos d'água, com diminuição da produtividade agrícola; corpos hídricos e mananciais poluídos por agrotóxicos; e conflitos fundiários. Além destes, há ainda a falta de planejamento de como gerir as águas superficiais oriundas das chuvas e de manejo destas águas visando sua manutenção no sistema e a proteção dos demais recursos naturais, sobretudo do solo.

No Estado de São Paulo, assim como em grande parte do país, praticamente quase todos os rios principais possuem elevada força hidráulica. Tal fato motivou diversas empresas de geração de energia a construir usinas em todo o Estado para atender à crescente demanda na região e prevenir uma possível crise energética (SANTOS, 2010), aliado à consolidação não apenas do setor de energia elétrica no país, mas também abarcando interesses das grandes empreiteiras responsáveis pela construção das obras civis das barragens e fabricantes de equipamentos, geralmente ligados às empresas multinacionais implantadas no país, sobretudo a partir das décadas de 1970 e 1980 (SANTOS, 1998). 
Além dos fatores mencionados, o governo estadual pretendia empreender uma política de desenvolvimento regional no Pontal do Paranapanema que visava solucionar ou minimizar as desigualdades regionais. A construção de usinas hidrelétricas se inseria neste contexto, considerando que o Pontal do Paranapanema é uma das regiões mais pobres do Estado.

Foi a partir deste contexto que surgiu em 1978, o "Programa para o desenvolvimento do Pontal do Paranapanema", com o intuito de integrar esta região à dinâmica do restante do território paulista. Entre os programas básicos destaca-se a implantação de uma Usina de Álcool, a Destilaria Alcídia, e três Usinas Hidrelétricas: UHE de Taquaruçu e UHE de Rosana (rio Paranapanema) e UHE Porto Primavera (rio Paraná), atualmente conhecida como UHE Engenheiro Sérgio Motta que foram iniciadas na década de 70 (ADORNO, 1990). Entretanto, o que se observa na atualidade é que estes empreendimentos pouco ou quase nada contribuem para o desenvolvimento regional do Pontal, privilegiando pequenas parcelas da população.

Para Teixeira et al (1998), os anos 70 são considerados o marco histórico do surgimento de grandes empreendimentos hidrelétricos nos países do chamado Terceiro Mundo. Estudos sobre esses grandes projetos no Brasil, com destaque para as hidrelétricas, demonstraram que estão estreitamente inter-relacionados com o modelo econômico nacional vigente e acentuam injustiças econômicas preexistentes nos territórios onde são instaladas, reforçando as disparidades econômico-sociais. Teixeira et al (1998) afirmam que esse processo está atrelado à expansão de um caráter transnacional na economia nacional que acaba por excluir governos estaduais e municipais e a sociedade civil dos processos decisórios que envolvem a implantação desses empreendimentos, ocasionando inadequação das tecnologias implementadas, que nem sempre são compatíveis com as condições de vida e com a vocação econômica dos territórios envolvidos. Isso tem resultado em sérios problemas em várias regiões do país no que se refere aos impactos ambientais provocados.

Assim, com base nos elementos pontuados até aqui fica evidente que pensar o desenvolvimento da região do Pontal do Paranapanema requer levar em consideração os conflitos ocasionados pela coesistência de diferentes modelos de desenvolvimento e dos consequentes distintos modos de uso da terra. Isso faz da Geografia entendida na perspectiva de sua totalidade - e não de modo fragmentado - uma importante referência não só teórica, mas também para a definição e execução de estratégias que visam promover não apenas o crescimento econômico regional, mas também a equidade social e a sustentabilidade no uso dos recursos naturais.

Contudo, as principais propostas de desenvolvimento regional implementadas no Pontal do Paranapanema não partem desse pressuposto, pois estão focadas 
principalmente na dimensão econômica da realidade. Podem ser citados os casos do "Plano de Desenvolvimento Econômico Local e Regional dos Municípios do Pontal do Paranapanema", da União dos Municípios do Pontal do Paranapanema (UNIPONTAL) (2014) e do "Plano Territorial de Desenvolvimento Rural Sustentável - Território Pontal do Paranapanema", do Conselho de Desenvolvimento Territorial do Pontal do Paranapanema (CODETER) (2010).

A UNIPONTAL é a associação dos prefeitos da região e visa, através da articulação política, atrair investimentos públicos e privados para o Pontal do Paranapanema. Em sua proposta de desenvolvimento consta como objetico central a implantação de "[...] ações que estimulem o crescimento econômico da região, bem como o do emprego e da renda" (UNIPONTAL, 2014). Assim, percebe-se que o desenvolvimento se confunde com o crescimento econômico. Em outros termos, a leitura de desenvolvimento foca em apenas uma das dimensões da realidade, no caso a econômica.

Por seu turno, o CODETER é uma colegiado formado por membros do Poder Público e da sociedade civil com o intuito de dar funcionalidade à abordagem territorial do desenvolvimento no Pontal do Paranapanema. A grande limitação de sua proposta de desenvolvimento (CODETER, 2010) é não levar em consideração a luta de classes como elemento estrutural. Isso porque, organizando diferentes representações sociais da região por meio do colegiado, acreditando na capacidade dessas estruturarem uma ação de desenvolvimento regional comum, o CODETER vê o modelo capitalista como totalidade e não busca sua superação. Isso redunda na prevelência de um modelo de desenvolvimento que coloca em centralidade o econômico frente as demais dimensões da realidade, caindo no mesmo erro da proposta apresentada pela UNIPONTAL (2014).

Ao contrário do conteúdo dessas duas propostas, defende-se aqui que pensar o desenvolvimento regional requer trabalhar com todas as dimensões da realidade como parte de um todo complexo. Evidentemente, isso exige ir além do modelo capitalista, pois esse está assentado na exploração da natureza para a geração de excedentes e não no convívio entre as esferas orgânica, inorgânica e humana.

\section{CONSIDERAÇÕES FINAIS}

O modelo de desenvolvimento capitalista está centrado na busca pela obtenção de lucros ampliados, o que exige a exploração irracional dos recursos naturais. A incompatibilidade dessa opção é a raiz das atuais crises climática, 
energética e alimentar, as quais colocam ênfase na necessidade de mudanças estruturais para a ocorrência de um desenvolvimento sustentável.

Nesse contexto, a Geografia se apresenta como de grande utilidade, na medida em que pode possibilitar a leitura da realidade por meio da totalidade e não de estratos separados. Evidentemente, para que isso ocorra, é preciso ir além da Geografia da modernidade industrial, que apoiada no positivismo e no neopositivismo leu a natureza como um elemento estanque da sociedade. A Geografia que se apresenta como recurso analítico e operacional para a denúncia e superação desse modelo excludente retoma o paradigma holista que caracterizou sua efetivação como saber científico na baixa modernidade e visa ler a natureza não somente como um conjunto de corpos organizados no espaço (MOREIRA, 2006), mas como uma unidade indissociável da própria sociedade.

Por isso, nesse trabalho foi defendida a assimilação do desenvolvimento regional como diferente do simples crescimento econômico. O primeiro é mais amplo que o segundo e para que promova a melhoria da qualidade de vida de toda a população, além do convívio harmônico com a natureza, é preciso ir além do capitalismo.

Tendo a região do Pontal do Paranapanema como recorte foi-se demonstrado que na atualidade coexistem diferentes modelos de desenvolvimento, contudo, a hegemonia é a do de cunho capitalista. Esse visa se impor sobre os territórios de camponeses/agricultores familiares e indígenas, homogeneizando a paisagem e desestruturando o trabalho.

\section{REFERÊNCIAS}

ADORNO, L. F. M. A implantação de Primavera e seus impactos ambientais. 1990. 97 f. Trabalho de conclusão de curso (Graduação em Geografia) - Faculdade de Ciências e Tecnologia, Universidade Estadual Paulista, Presidente Prudente.

COCA, E. L. F. A soberania alimentar através do Estado e da sociedade civil: 0 Programa de Aquisição de Alimentos (PAA), no Brasil e a rede Farm to Cafeteria Canada (F2CC), no Canadá. 2016. Tese (Doutorado em Geografia). Faculdade de Ciências e Tecnologia da Unesp, campus de Presidente Prudente.

CODETER - CONSELHO DE DESENVOLVIMENTO TERRITORIAL DO PONTAL DO PARANAPANEMA (CODETER). Plano Territorial de Desenvolvimento Rural Sustentável - Território Pontal do Paranapanema. São Paulo, 2010.

FELICIANO, C. A. Movimento camponês rebelde: a reforma agrária no Brasil. São Paulo: Editora Contexto, 2006.

FELICIANO, C. A. Territórios em disputa: terras (re) tomadas no Pontal do Paranapanema. 2009. Tese (Doutorado em Geografia Humana). Universidade de São Paulo (USP), São Paulo.

FERNANDES, B. M. Espacialização e territorialização da luta pela terra: a formação do MST - Movimento dos Trabalhadores Rurais Sem Terra no Estado de 
São Paulo. 1994. Dissertação (Mestrado em Geografia Humana) Universidade de São Paulo (USP), São Paulo.

IBGE - INSTITUTO BRASILEIRO DE GEOGRAFIA E ESTATATÍSTICA. Censo Agropecuário de 2006. Rio de Janeiro, 2006.

ITESP - INSTITUTO DE TERRAS DO ESTADO DE SÃO PAULO. Pontal verde: plano de recuperação ambiental nos assentamentos do Pontal do Paranapanema. São Paulo: ITESP, 1999. Série Cadernos ITESP n²/Secretaria da Justiça e Defesa da Cidadania.

LEAL, A.C. Gestão das Águas no Pontal do Paranapanema - São Paulo. 2000. 299 p. Tese (Doutorado em Geociências - Área de concentração em Administração e Política de Recursos Minerais) - Instituto de Geociências - UNICAMP, Campinas.

LEFF, E. Epistemologia ambiental. São Paulo: Cortez, 2006.

LEITE, J. F. A ocupação do Pontal do Paranapanema. São Paulo: Hucitec, 1998.

LENCIONI, S. Região e Geografia. São Paulo: EdUSP, 1999.

MACIEL, M. C. Tupanciretrã: Deus passou por aqui. 2009. Um estudo sobre as relações entre os movimentos sociais e as religiões nos assentamentos rurais Primavera e Tupanciretã no Pontal do Paranapanema/SP. Tese (Doutorado em Sociologia). Universidade de São Paulo (USP), São Paulo

MAZZINI, E. Assentamentos rurais no Pontal do Paranapanema - SP: uma política de desenvolvimento regional ou de compensação social? 2007. Faculdade de Ciências e Tecnologia da Unesp, campus de Presidente Prudente.

MONBEIG, P. Pioneiros e fazendeiros de São Paulo. São Paulo: Hucitec, 1984.

MOREIRA, R. Para onde vai o Pensamento Geográfico? Por uma epistemologia crítica. São Paulo: Contexto, 2006.

REDE DATALUTA. Relatório DATALUTA. In: VINHA, J. F. S. C.; COCA, E. L. F.; FERNANDES, B. M. (eds.). DATALUTA: Questão Agrária e coletivo do pensamento. São Paulo: Expressão Popular, 2014.

RODRIGUEZ, J. M. M.; SILVA; E. V. da. Educação ambiental e desenvolvimento sustentável: problemática, tendências e desafios. Fortaleza: Edições UFC, 2009.

SANTOS, R. dos. Meio ambiente e qualidade de vida na Estância Turística de Presidente Epitácio - São Paulo. 2010. 374 f. Dissertação (Mestrado em Geografia) - Faculdade de Ciências e Tecnologia, Universidade Estadual Paulista, Presidente Prudente.

SANTOS, V. L. dos. Projetos hidrelétricos de grande porte e efeitos sociais: 0 exemplo do topocídio provocado pela barragem de Porto Primavera. 1998. $220 \mathrm{f}$. Dissertação (Mestrado em Geografia) - Instituto de Geociências e Ciências Exatas, Universidade Estadual Paulista, Rio Claro.

SOBREIRO FILHO, J. O movimento em pedaços e os pedaços em movimento: da ocupação do Pontal do Paranapanema à dissensão nos movimentos socioterritoriais camponeses. 2013. Dissertação (Mestrado em Geografia). Faculdade de Ciências e Tecnologia da Unesp, campus de Presidente Prudente.

TEIXEIRA, M. G. et al. Análise dos relatórios de impactos ambientais de grandes hidrelétricas no Brasil. In: AB' SABER, A. N.; MÜLLER-PLANTEBERG, C. (Org.).

Previsão de Impactos: o estudo de impacto ambiental no leste, oeste e sul. Experiências no Brasil, na Rússia e na Alemanha. São Paulo: Edusp, 1998. p. 163186. 
THOMAZ JÚNIOR, A. O novo ambiente institucional na agroindústria canavieira paulista, no âmbito da câmara setorial e a luta pela terra. Uma peleja para a classe trabalhadora. Revista Pegada, Presidente Prudente, v. 14, p. 3-38, 2013.

UNIPONTAL - UNIÃO DOS MUNICÍPIOS DO PONTAL DO PARANAPANEMA. Plano de Desenvolvimento Econômico Local e Regional dos Municípios do Pontal do Paranapanema. Presidente Prudente, 2014.

\footnotetext{
1 Ricardo dos Santos. Instituição a que pertence e função: Doutorando em Geografia pela Universidade Estadual Paulista - UNESP, campus de Presidente Prudente. Bolsista CAPES. Endereço profissional: Universidade Estadual Paulista, Faculdade de Ciências e Tecnologia, campus de Presidente Prudente. Rua Roberto Simonsen, № 305, Centro Educacional. CEP: 19.060-900 - Presidente Prudente/SP. E-mail: ricasantos2000@yahoo.com.br

${ }^{2}$ Estevan Leopoldo de Freitas Coca. Instituição a que pertence e função: Doutor em Geografia pela Universidade Estadual Paulista - UNESP, campus de Presidente Prudente. Professor Colaborador da Universidade Estadual de Londrina - UEL. Endereço profissional: Universidade Estadual de Londrina - Departamento de Geociências. Rodovia Celso Garcia Cid, Campus Universitário, PR 445, Km 380. CEP: 86.057-970 - Londrina/PR. E-mail: estevancoca@uel.br

${ }^{3}$ De acordo com Sobreiro Filho (2013) outras denominações dadas ao MST da Base são: "MST do Rainha"; "MST do Zé"; "Grupo do Zé"; e "Grupo do Rainha".
} 